\title{
Crianças pequenas na escola: contradições e potencialidades
}

Juliana Pasqualini ${ }^{1}$

Lucineia Lazaretti ${ }^{2}$

\begin{abstract}
Resumo
Na sociedade capitalista contemporânea a atividade social da criança pequena encontra-se largamente situada no interior de instituições de educação infantil. Este artigo recupera as origens e o desenvolvimento histórico das instituições de educação infantil, analisando as necessidades societárias concretas em função das quais essa prática social se instituiu e institucionalizou-se. Nesse percurso, evidencia que a consolidação da educação infantil como prática institucional respondeu historicamente a motivações extrínsecas, essencialmente econômicas e ideológicas, ao mesmo tempo que abriu a possibilidade histórica de converter em objeto de pesquisa e debate social as melhores condições possíveis para o desenvolvimento e a educação da criança pequena. Refletir sobre a escola de educação infantil como conquista histórica que, embora não isenta de contradições, contém a potencialidade de enriquecer a formação humana da criança, é a proposta desse ensaio, que problematiza as concepções de desenvolvimento infantil e de criança subjacentes aos projetos historicamente em disputa para etapa educacional. A aposta no ensino desenvolvente é o caminho que se indica como potencialidade de a escola de educação infantil constituir-se como espaço de atividades significativas e formativas para as crianças até os cinco anos de idade.
\end{abstract}

Palavras-chave: Crianças pequenas, Educação infantil, Ensino desenvolvente.

\section{Young children in nursery schools: contradictions and potentialities}

\begin{abstract}
In contemporary capitalist society, the social activity of small children is largely situated within early childhood education institutions. This article recovers the origins and historical development of early childhood education institutions, analyzing the specific societal needs according to which this societal practice was instituted and institutionalized. In this way, it shows that the consolidation of early childhood education as an institutional practice has historically responded to extrinsic motivations, essentially economic and ideological, while opening the historical possibility of converting the best possible conditions for development and social development into an object of research and social debate. Reflect on the nursery scholls as a historical achievement that, although not free from contradictions, contains the potential to enrich the human education of the child, is the proposal of this essay, which problematizes the conceptions of child and child development underlying the educational projects historically in dispute. Developmental teaching is presented as a path that realizes the potential for the early childhood school to be a space for meaningful and formative activities for children up to five years of age.

Keywords: Small children, Nursery school, Developmental teaching.
\end{abstract}

\footnotetext{
${ }^{1}$ Doutora em Psicologia pela UNESP Araraquara. Pós Doutora pela UNICAMP. Professora do Departamento de Psicologia da UNESP Bauru e do Programa de Pós-Graduação em Educação Escolar da UNESP Araraquara. Orcid: https://orcid.org/0000-0002-6497-8783. E-mail: pasqualinijc@gmail.com.

${ }^{2}$ Doutora em Educação pela Universidade Federal de São Carlos. Professora Adjunta na Universidade Estadual do Paraná (campus de Paranavaî). É integrante do Grupo de Pesquisa e Ensino “Trabalho Educativo e Escolarização” (GENTEE/UEM). Orcid: https://orcid.org/0000-0003-3878-8158. E-mail: lucylazaretti@gmail.com.
} 


\section{Palavras Iniciais}

O lugar que a criança ocupa na sociedade é aspecto primordial para se analisar as práticas sociais a ela destinadas e as possibilidades concretamente dadas para seu desenvolvimento. Ensina Bozhovich (1981, p.99) que "a condição fundamental que determina a formação da personalidade do homem é o lugar que ele ocupa no sistema de relações sociais e a atividade que [desde esse lugar] ele mesmo cumpre/realiza". Também orientado por uma ontologia materialista histórica dialética, Leontiev (1988) postula que "o que determina diretamente o desenvolvimento da psique de uma criança é sua própria vida e o desenvolvimento dos processos reais desta vida - em outras palavras: o desenvolvimento da atividade da criança (...)” (p. 63). Para a psicologia histórico-cultural, a atividade constitui a conexão mediadora entre indivíduo e realidade social, colocando em movimento processos psíquicos e assim instituindo neoformações do psiquismo - novas operações psicológicas que se sintetizam em novas capacidades de ação, requalificando os modos de perceber, sentir e agir no mundo. A categoria atividade é fundamental para o estudo da infância concreta, pois convoca ao exame do conteúdo da vida da criança.

Refletir sobre a escola de educação infantil como prática institucional no interior da qual se tece a atividade da criança pequena é a proposta desse ensaio. Objetivamos evidenciar a persistência de contradições históricas que marcaram a trajetória de constituição da educação infantil e que se expressam na tensão entre a reprodução de processos alienantes e a possibilidade de promoção do desenvolvimento humano. Para tanto, recuperamos a história de consolidação da educação infantil, problematizando as concepções de desenvolvimento e de criança subjacentes aos projetos em disputa para essa etapa educacional e apontando o ensino desenvolvente como caminho para realizar a potencialidade histórica de fazer da escola de educação infantil um espaço de atividades significativas e formativas para as crianças até os cinco anos de idade.

Criança-carente: a desigualdade como marca da trajetória histórica da educação infantil

A provisão de atendimento institucional para crianças pequenas foi inicialmente motivada pela necessidade de proteção e cuidado a crianças vítimas de abandono ou em 
condição de extrema pobreza, mas principalmente pela necessidade de cuidado das crianças oriundas de famílias da classe trabalhadora, particularmente quando as mulheres se tornaram parte importante da força de trabalho. A análise das origens e desenvolvimento histórico da educação infantil nos revela que essa prática social surge e se estabelece como tal na sociedade capitalista.

A criação de instituições voltadas à criança pequena é parte de uma tendência mais ampla de institucionalização das práticas de cuidado em geral, incluindo, por exemplo, o cuidado com idosos e enfermos, como uma necessidade resultante das transformações das estruturas familiares e comunitárias engendradas pelos processos socioeconômicos de industrialização.

Instituições religiosas e filantrópicas conhecidas como "salas de asilo" ou "salas de custódia" surgiram em Paris em fins do século XVIII, funcionando em regime de internato, com objetivo amparar a infância pobre (em especial crianças órfãs e abandonadas) e reduzir as altas taxas de mortalidade nos primeiros anos de vida (KISHIMOTO, 1988; OLIVEIRA, 2005). Embora o atendimento se realizasse em condições bastante precárias, havia desde os primeiros textos oficiais, conforme Kuhlmann Junior (2007), a perspectiva de prover cuidados e educação moral e intelectual às crianças.

A primeira crèche foi criada em 1844, em Paris, num contexto em que, em função da necessidade do trabalho, mães operárias abandonavam seus filhos pequenos em asilos ou aos cuidados de "amas mercenárias" e até de outras crianças mais velhas, condições que favoreciam o aumento da mortalidade infantil e mesmo o infanticídio. Segundo Kishimoto (1988), 40 anos após a criação da primeira creche já haviam se estabelecido aproximadamente 200 em toda a França, funcionando todos os dias, com exceção de domingos e dias de festa, das 5:30h às 20:30h - dado revelador da extensão das jornadas de trabalho à época (CIVILETTI, 1991).

Conforme Civiletti (1991) a creche, destinada a crianças de 0 a 2 anos, e as salas de asilo e escolas maternais, que atendiam até crianças de 3 a 6, inseriam-se, de acordo com os ideais liberais da época, no esforço educacional de "orientar" ou "instruir" as classes populares, expressão da contradição que permeia a constituição da nova sociedade: orienta-se pela ideia de libertar o homem dos vínculos, ordens e limites, mas também pretende moldar o 
indivíduo de acordo com os modelos sociais modernos de comportamento produtivo e integrado.

Ao liberar a mão-de-obra feminina e melhorar o rendimento da masculina, as salas de asilo e escolas maternais francesas eram abertas gratuitamente a todas as mães que não pudessem pagar a contribuição mensal, mas tinham como usuário preferencial o filho do operário, cuja finalidade era "diminuir o número de seres inúteis e perigosos" e "aumentar o número de trabalhadores vigorosos" (CIVILETTI, 1991), por meio de exercícios intelectuais e físicos, em um regime militar de funcionamento institucional. Caracterizando a atividade das crianças nestas instituições, que disseminando-se pela Europa até a Rússia, Oliveira (2005, p.17) descreve que, em suas instalações, até “(...) 100 crianças pequenas obedeciam a comandos dos adultos dados por apitos”. Kishimoto (1988) aponta que a arraigada tradição assistencialista não permitiu o "florescimento" da nova escola maternal: sua prática consistia em "longos exercícios de leitura coletiva, em sucessão monótona, ensurdecedora e ininteligível de letras, sílabas e palavras.” (p. 59).

No Brasil, as primeiras creches instaladas no início da República confundiam-se com os asilos infantis, atendendo basicamente crianças órfãs e filhos de indigentes em regime de internato. Destinadas a minimizar os graves problemas sociais decorrentes do processo de urbanização, atendiam principalmente o contingente de mulheres e crianças na extrema miséria, que aumentava nos núcleos urbanos em função do deslocamento de populações pobres, em busca de melhores condições de vida. $\mathrm{O}$ atendimento era em geral realizado sob péssimas condições de higiene, funcionando como verdadeiros depósitos de crianças (KISHIMOTO, 1988). A posterior difusão dessa instituição esteve estreitamente ligada ao desenvolvimento da atividade industrial e à consequente demanda por mão-de-obra feminina.

Três aspectos da organização histórica das creches no Brasil merecem destaque: i) o atendimento oferecido era essencialmente assistencialista e tutelar, sendo tais instituições ligadas ao âmbito da assistência social, vinculadas a associações filantrópicas ou religiosas e algumas poucas a empresas, atendendo basicamente à necessidade de cuidar das crianças enquanto as mães trabalhavam; ii) não era exigida formação profissional para se trabalhar nessas instituições, pois acreditava-se que as habilidades maternais, supostamente naturais, qualificavam toda e qualquer mulher a desempenhar a função de guarda e cuidado de crianças 
(posto que o objetivo era simplesmente fornecer alimentação, higiene, segurança); iii) destinavam-se às mulheres pobres e "de boa conduta" que trabalhavam fora de seu domicílio, entendidas, portanto, como um "mal necessário". Como destaca Civiletti (1991), naquele momento histórico "as regras estavam socialmente bem definidas: às mulheres das classes abastadas, destinava-se a maternidade: às pobres, o trabalho" (p.39). Sobre aquelas impedidas pelas condições de vida de exercer a maternidade segundo os ideais da época, recaía uma culpabilização mais ou menos implícita.

Vê-se que necessidades de ordem essencialmente econômica e ideológica determinaram historicamente a proliferação de creches e escolas maternais destinadas aos filhos dos trabalhadores: a liberação e conformação da força-de-trabalho (por meio da guarda dos filhos durante a jornada de trabalho das mães) e a conformação da futura força-detrabalho (por meio da ação disciplinar). Tais condições passaram a ser garantidas (total ou parcialmente) por uma nova prática social - o atendimento institucional à pequena infância proletária, para atender a criança-carente.

De forma paralela à difusão de creches e escolas maternais, outro modelo institucional de atenção à criança pequena surgiu e se estabeleceu historicamente: os jardins-de-infância. $O$ primeiro kindergarten foi fundado por Friedrich Froebel em 1840, na Alemanha, destinado a crianças de 3 a 7 anos. O principal objetivo dessa instituição era propiciar o desenvolvimento intelectual, emocional, físico, social e moral da criança, principalmente pelo uso de jogos, atividades de formação religiosa, cuidado com o corpo, observação da natureza, aprendizagem de poesias e cantos, exercícios de linguagem, desenho, canto, viagens e passeios. O jardim-de-infância teve ampla penetração em diversos países, e embora tenha sido idealizado para atender crianças de famílias pobres moradoras das periferias e favelas alemãs, espalhou-se no Brasil e em outros países como um privilégio das famílias das classes abastadas (KISHIMOTO, 1988).

O primeiro jardim-de-infância público foi criado no Brasil em 1896, anexo à Escola Normal Caetano de Campos, em São Paulo. Cercado por um grande jardim, com salas de aula, um salão central, terraços com vistas para diferentes pontos da cidade e dois pavilhões cobertos para recreação dos alunos, a instituição tinha suas vagas destinadas às crianças das "melhores famílias paulistanas" (MARCELINO, 2004). Enquanto filhos de famílias trabalhadoras precisavam ter atendidas suas necessidades mínimas de higiene, nutrição e 
proteção como condição para que suas mães se dedicassem ao trabalho cotidiano, filhos das famílias abastadas deveriam ter seu desenvolvimento estimulado. Tal fragmentação econômico-social também pode ser observada no padrão de atendimento de países europeus (KISHIMOTO, 1988) e subsistiu durante toda a história do atendimento institucional à pequena infância brasileira.

É decisivo perceber que o atendimento às crianças das classes populares em creches e instituições similares continha em si também um projeto educacional (KUHLMANN JR., 2007). Pasqualini e Martins (2008) asseveram a impossibilidade de se dissociar cuidado e educação, no sentido de que é impossível cuidar de crianças sem educá-las de alguma forma e em alguma direção. Para Kuhlmann Jr. (2007, p. 166-7), o assistencialismo pode ser compreendido como uma proposta educacional dirigida à criança-carente: "o fato de essas instituições carregarem em suas estruturas a destinação a uma parcela social, a pobreza, já representa uma concepção educacional." Acrescenta o autor que, por meio de um atendimento de baixa qualidade, se "pretende preparar os atendidos para permanecerem no lugar social a que estariam destinados", o que pode ser interpretado como uma pedagogia da submissão.

A análise de Kuhlmann Jr. (2007) desvela a função de apaziguamento das relações sociais exercida por creches e escolas maternais destinadas à infância pobre, evidenciando seu papel no processo mais amplo de reprodução social. O autor utiliza a expressão "educando o pobre para proteger o rico" para demarcar esse papel desempenhado pelas instituições préescolares junto à população pobre que ameaçava a tranquilidade das elites.

Com o aumento da industrialização e a urbanização no país nos anos 1960, houve um grande aumento no número de mulheres inseridas no mercado de trabalho e as creches e parques infantis que atendiam crianças em período integral passaram a ser cada vez mais procuradas por trabalhadoras domésticas, do comércio e operárias e também por funcionárias públicas. Nesse período, o golpe militar de 1964 determinou uma profunda mudança na ação governamental dirigida à infância, a qual, segundo Merisse (1997), passou a orientar-se por um paradigma assistencialista e repressor.

Nas décadas de 1960 e 1970 ganham força no Brasil ideias vinculadas à teoria da privação cultural, gestada nos Estados Unidos em fins da década de 1950 e início de 1960. Em linhas gerais, preconizava que os altos índices de fracasso escolar de crianças de nível 
socioeconômico baixo se explicariam por deficiências culturais, nutricionais e afetivas dessas crianças, cujo ambiente familiar não favoreceria um desenvolvimento psicológico saudável. Nesse contexto, observamos um estímulo à implantação de programas de educação préescolar, concebidos como uma "solução" para o fracasso das crianças pobres na escola ao enfrentar o problema da "privação cultural" das crianças e famílias, compensando as supostas carências culturais, nutricionais e afetivas dos alunos. Merisse (1997, p. 46) salienta que, em tal concepção: "a escola e a própria estrutura social como um todo eram poupadas em suas responsabilidades, que seriam convenientemente transferidas à própria "criança carente"”.

A educação pré-escolar assume um caráter preparatório e compensatório, tendo como perspectiva: difundir o atendimento pré-escolar para elevar o nível de aproveitamento da escolaridade obrigatória; reduzir a distorção idade/série na escola primária; reduzir as taxas de evasão e repetência na primeira série (e consequentemente os índices de analfabetismo no país) como estratégia de prevenção do fracasso escolar. Todas essas apostas sintetizam uma meta maior de "combate à pobreza" e à desnutrição em países subdesenvolvidos, como o Brasil, a partir da década de 1970 e 1980, com programas de educação pré-escolar incentivados por organismos internacionais como a UNICEF e a UNESCO, e a partir da década de 1990 o Banco Mundial. De acordo com Rosemberg (2002) esses programas preconizavam modelos não-formais e a baixo custo, recorrendo a espaços inadequados e improvisados, materiais, equipamentos e recursos humanos improvisados na "comunidade", o que se justificaria diante da escassez orçamentária e da prioridade de universalização do ensino fundamental em um país subdesenvolvido. Em síntese, indica-se o barateamento e a improvisação de condições e recursos quando o sujeito do atendimento é a criança-carente ${ }^{1}$.

A educação pré-escolar compensatória desempenha um papel claramente ideológico, ocultando os reais determinantes do fracasso escolar e sustentando a falsa ideia de que é possível superar a pobreza pela via educacional. Contraditoriamente, sua difusão chama atenção para o potencial que o cuidado e a educação de qualidade podem ter na superação ou minimização de problemas no desenvolvimento das crianças de baixa ou baixíssima renda. Por isso, em sociedades caracterizadas por profundas desigualdades sociais, como o Brasil, a educação infantil figura como uma "ferramenta" para minimizar os efeitos deletérios da

\footnotetext{
${ }^{1}$ Merisse (1997) aponta que o conceito de "criança carente" supõe uma inferioridade em relação a um padrão estabelecido, o que evidencia que o trabalho desenvolvido nas instituições de ensino pré-escolar foi historicamente informado por uma visão ideológica e preconceituosa em relação às famílias e crianças pobres.
} 
pobreza sobre o desenvolvimento das crianças, contribuindo para prevenir problemas de saúde e desenvolvimento nas famílias de baixa renda, como estratégia duradoura para o desenvolvimento econômico. Cumpre, assim, uma função no processo de reprodução social que perpetua um modo de vida no qual a efetiva superação da pobreza não se coloca como horizonte.

Em termos pedagógicos, a pré-escola que prepara as crianças pobres para a escola primária visando combater o fracasso escolar se caracteriza pela importação de formas e conteúdos típicos da escola primária, sem a preocupação com sua pertinência ou adequação às características e especificidades da faixa etária atendida. Dominam a cena tarefas vinculadas à preparação para a alfabetização e ao treino de habilidades motoras, firmando-se como hegemônica a imposição de rígidas rotinas e tarefas desprovidas de sentido para as crianças, meramente exercitando habilidades de forma mecânica, fenômeno que viria posteriormente a ser alvo de críticas pedagógicas e caracterizado como "antecipação da escolarização".

A perspectiva de preparação das crianças pobres para a escola expressa historicamente menos uma preocupação com o desenvolvimento cognitivo-afetivo e mais a produção da adaptabilidade ou ajustamento dessa criança ao ambiente escolar, tendo em vista a redução formal dos níveis de repetência, evasão e distorção idade/série. Vistas sob a ótica da inferioridade e da carência, as crianças eram submetidas precocemente à ambiência da instituição escolar, à qual se esperava que elas se ajustassem, com claro sentido de produção da prontidão. Ao arsenal típico das escolas primárias, com carteiras fixas e material mimeografado, pontua Rosemberg (2002, p. 5), "acrescentou-se a sucata".

\section{Criança-cidadã: a educação infantil como direito e o problema da especificidade}

A partir dos anos 1970, ocorre, no Brasil, uma articulação de movimentos sociais na luta pela ampliação da rede de atendimento pré-escolar, com forte pressão sobre o poder público para a instalação desses equipamentos, no contexto de uma luta por direitos sociais e cidadania.

Kuhlmann Jr. (2007) destaca que a luta por creches integrava e se articulava a lutas e movimentos sociais que se generalizavam naquele momento histórico, incluindo greves, manifestações estudantis, passeatas pelas liberdades democráticas, entre outros. A creche 
passou a ser sinônimo de conquista. As propostas feministas e o próprio Movimento de Luta por Creches contribuíram não só para a ampliação e melhoria no atendimento oferecido nas creches destinadas à população de baixa renda, mas também para uma nova compreensão sobre a creche: essa instituição não deveria mais ser vista como um mal necessário, e sim como uma alternativa que poderia ser organizada de forma saudável e apropriada para a criança, desejável à mulher e à família, em suma, como um direito da mulher e da criança. Esse processo influenciou também as camadas médias da população, que passaram a apresentar uma crescente demanda pelo serviço de creche ou similares (MERISSE, 1997).

A compreensão da educação infantil como direito da criança e da mulher se concretizou na Constituição de 1988 que, como se sabe, foi fruto de intensos processos de mobilização social. Nela se apresenta pela primeira vez a educação infantil como uma extensão do direito universal à educação para as crianças menores de 6 anos, bem como um direito de homens e mulheres trabalhadores a terem seus filhos cuidados e educados em creches e pré-escolas. Nesse sentido, o atendimento pré-escolar é também concebido como instrumento para igualdade de oportunidades de gênero, ao apoiar o trabalho feminino extradoméstico (ROSEMBERG, 2002).

Com a promulgação da nova Constituição, a Coordenação de Educação Infantil do Ministério da Educação (COEDI/ MEC), estabeleceu diretrizes gerais sobre a política para essa etapa escolar, propondo metas de expansão com atendimento de qualidade e afastando-se do modelo não-formal e a baixo custo. O documento "Política Nacional de Educação Infantil”, publicado em 1993, estabelece, entre outras coisas, a equivalência de creches e préescolas e a formação equivalente para os profissionais de ambas as instituições. Tais proposições, conforme Rosemberg (2002), foram elaboradas num período em que os organismos internacionais pouco atuaram na área de educação infantil em nosso país, contando com a participação de pesquisadores, movimentos sociais e sociedade civil, num processo que representou um avanço na direção da democratização dessa etapa escolar no Brasil. A autora ressalta, contudo, que a implementação de tais propostas foi interrompida no Governo Fernando Henrique Cardoso, que incorporou as determinações político-econômicas do Banco Mundial, que no tocante à educação infantil representavam “(...) a retomada da proposta de programas 'não formais' a baixo investimento público de EI para crianças pequenas pobres" (p. 42). 
Em meio a tal contexto, foi promulgada a nova Lei de Diretrizes e Bases da Educação Nacional (LDB) em 1996. Embora traga em seu bojo uma concepção liberal de educação e tenha caráter mais propriamente indicativo do que prescritivo, em pouco alterando efetivamente a situação das escolas públicas brasileiras (SAVIANI, 1997), é forçoso reconhecer que, do ponto de vista da história da educação infantil, a LDB/96 traz avanços decisivos. Primeiramente, na medida em que institui a educação infantil como primeira etapa da Educação Básica, a Lei conserva o princípio da equivalência entre creches e pré-escolas, determinando - pela primeira vez - a inserção das creches nos sistemas de ensino municipais. Kuhlmann Jr. (2007, p. 186) destaca o avanço representado pela vinculação das creches ao sistema de ensino como condição necessária (embora não suficiente) para superação da perspectiva da educação assistencialista, pois se passa a fazer parte do sistema educacional do país, a creche "(...) deixa de ser apresentada como alternativa para pobres incapazes, para ser posta como complementar à ação da família, tornando-se uma instituição legítima e não um simples paliativo."

Vemos assim consolidar-se a concepção da educação infantil como direito da criança no esteio do reconhecimento da condição da criança como sujeito de direitos, isto é, do reconhecimento de direitos específicos e inerentes à condição infantil. A educação infantil, como primeira etapa da educação básica, consolidou-se em meio a um pluralismo de ideais e num período de ascensão do projeto democrático de sociedade, e, do ponto de vista social, histórico e político, foi uma conquista da e para a classe trabalhadora.

Não obstante, no plano concreto o que se observa mais de 30 anos após a promulgação da Constituição e mais de 20 anos depois da promulgação da LDB é que a universalização da oferta de atendimento pré-escolar ainda não se tornou realidade no Brasil e que o acesso a uma educação infantil de qualidade é ainda uma utopia para a esmagadora maioria da população infantil brasileira. Tal discrepância entre o plano do discurso e o plano da realidade concreta não é, certamente, fortuita ou mesmo inesperada.

O que se constata, em suma, é que a ideia da criança-cidadã, sujeito de direitos, apresentou-se como consenso proclamado no plano ideal/ formal, sem que esse ideal representasse uma efetiva superação das precárias condições de vida a que são submetidas grande parte das crianças brasileiras. Em tese, a perspectiva de se prover melhores condições 
de desenvolvimento e educação, antes circunscrita às crianças da elite, passa a ser defendida como direito também das crianças das classes populares; no entanto, as políticas públicas para o segmento estão muito distantes de promover a superação da fragmentação socioeconômica no atendimento à pequena infância, concorrendo, ainda hoje, para sua manutenção. Saviani (1997) assevera que essa contradição entre o plano jurídico-formal (igualdade formal) e o plano da vida concreta das pessoas (desigualdade real), marca da ideologia liberal, se materializa na Lei de Diretrizes e Bases da Educação de 1996, em que os objetivos proclamados não coincidem e, em última instância, mascaram os objetivos reais.

No plano dos ideários pedagógicos, observamos que a consolidação da concepção da criança como sujeito de direitos no Brasil se articula à afirmação de ideias pós-modernas no campo da educação infantil, que se presentificam no momento histórico em que se coloca um novo problema a ser enfrentado e elucidado por profissionais, pesquisadores e gestores: a especificidade do trabalho educativo na educação infantil.

A trajetória histórica aqui exposta deixa claro que as finalidades que orientaram a consolidação da educação infantil como prática institucional foram mormente extrínsecas, liberando a força de trabalho, evitando a desordem social, compensando os efeitos mortificadores da miserabilidade, preparando para a entrada na escola, prevenindo o futuro fracasso escolar. O movimento que culmina no reconhecimento formal da educação infantil como direito da criança e reafirma o caráter centralmente educativo do trabalho realizado nessas instituições, coloca no horizonte o desafio de superação desse legado entranhado de contradições e mazelas. Os debates em torno de uma proposta para a educação que resguardasse a especificidade do trabalho pedagógico dirigido a crianças menores de seis anos foram marcados por algumas tônicas: a rejeição de uma identidade assistencialista, circunscrita à tarefa da guarda e tutela das crianças pequenas, que marcou especialmente a história das creches; a reafirmação do caráter profissional do trabalho realizado (demarcando a fronteira entre o profissional e o doméstico no atendimento institucional à criança pequena); e a negação do caráter compensatório e preparatório do atendimento pré-escolar.

A recusa a essa herança marcada por práticas antecipatórias, mecânicas, descontextualizadas e esvaziadas de sentido para a criança pequena, veio a se expressar na defesa de uma identidade para a educação infantil assentada na defesa do binômio cuidareducar e no afastamento da escola e do modelo escolar. Vemos emergir um movimento 
teórico que se apoia na defesa do direito à infância, preconizando, como condição para sua garantia, o rompimento dos vínculos do atendimento educacional à criança pequena com a educação escolar, sintetizada em uma pedagogia anti-escolar.

Trata-se da perspectiva da Pedagogia da Infância (CERISARA, 2004; KISHIMOTO; PINAZZA, 2007; ROCHA, 1999), cujos princípios podem assim ser sintetizados: i) uma concepção de criança como protagonista do processo educativo e produtora de cultura; ii) a defesa de um processo educativo direcionado pelos interesses, impulsos e necessidades imediatas da criança; iii) o papel do professor reduzido a "seguir as crianças", acompanhando, oferecendo suporte, organizando situações e registrando as experiências; iv) valorização das experiências espontâneas emergentes do círculo cultural de cada criança, em detrimento de um programa curricular; v) compreensão das instituições de educação infantil como espaços de convívio coletivo que fornecem cuidado e educação (mas não ensino) (LAZARETTI, 2013).

Esses princípios conquistam a hegemonia no âmbito das políticas educacionais para a educação infantil na virada para o século XXI, materializando-se em diversos documentos oficiais, com destaque às Diretrizes Curriculares Nacionais para a Educação Infantil (2009) e à mais recentemente promulgada Base Nacional Comum Curricular (2017).

Em síntese, o ideário da Pedagogia da Infância vincula a concepção de criança como sujeito de direitos (criança-cidadã) à noção de uma criança protagonista de seu próprio percurso formativo, sugerindo que a interferência do mundo adulto deve ser minimizada por seu caráter fundamentalmente cerceador da espontaneidade e liberdade infantis. Por esse caminho, chega-se à negação da própria ideia de um currículo escolar voltado à criança pequena, o que se expressa na proposição dos campos de experiências como arranjo curricular pela BNCC. Isso contribui para fixar alguns dualismos que pouco colaboram para, de fato, direcionar e organizar a prática pedagógica: diretividade do professor $o u$ atividade do aluno; currículo escolar ou interesses infantis; conteúdos de ensino ou experiências infantis.

Em nome de garantir uma identidade a esse segmento educativo e de um suposto respeito à condição infantil, tal movimento, em nossa avaliação, termina por descaracterizar e negar a escola como um espaço privilegiado para a educação das crianças pequenas, redundando na sonegação do direito ao conhecimento historicamente acumulado da e na 
experiência humana em um período da vida que se mostra decisivo para a formação das bases da concepção de mundo e da personalidade. A posição que sustentamos é que, paradoxalmente, ao se atribuir à criança o lugar de protagonista do processo educativo, impõem-se barreiras a seu desenvolvimento, por mantê-la circunscrita a suas experiências individuais, espontâneas, cotidianas. Retira-se da escola a tarefa decisiva de enriquecer e desafiar a atividade infantil, guiando os pequenos na aventura de conhecer, compreender e aprender a atuar no mundo.

\section{A criança concreta e a aposta no ensino escolar desenvolvente}

A concepção que posiciona a criança como protagonista de seu próprio processo formativo pode ser problematizada à luz da perspectiva histórica e dialética, que demarca como aspecto central do estudo do desenvolvimento infantil a relação criança-sociedade (ELKONIN, 1987). A criança vive necessariamente em relação e, como criança concreta, é preciso compreender que seu processo de formação se dá no seio das condições materiais e sociais de vida e educação, sendo sua atividade forjada essencialmente pelas relações que estabelece com as demais pessoas que compõem sua realidade circundante.

Para Mùjina (1979) e Elkonin (1987), a relação criança-adulto, desde os primeiros meses de vida, tem caráter de atividade compartilhada, atividade essa que, orientada pelo par mais experiente - o adulto - desafia o psiquismo infantil, assim provocando a complexificação dos processos psíquicos. Essa atividade compartilhada e instruída é decisiva para a formação da criança pequena pois, como ensina a psicologia histórico-cultural, para desenvolver qualidades humanas, integrando-se ao gênero humano, cada novo ser deve se apropriar da riqueza material e imaterial objetivada na cultura humana. Tal processo não se dá pela interação espontânea e direta da criança com a cultura no seio da sociedade, mas por uma relação criança-sociedade que é mediada pela prática educativa, que organiza, orienta, guia e delineia os conteúdos sociais da atividade da criança. O que se está aqui afirmando é, em primeiro lugar, que o conteúdo da atividade da criança não emerge dela mesma ou de sua interação espontânea com o entorno, mas é engendrado na e pela sociedade, em função do lugar social designado à criança (pobre, rica, branca, negra, indígena, portadora de deficiência, do sexo masculino ou feminino etc.) na prática social. Em segundo, que o adulto não meramente acompanha, estimula e incentiva a atividade infantil, mas a organiza e 
determina seu conteúdo social e cultural de modo a reconstituir no âmbito da singularidade a atividade histórica do gênero humano.

À luz dessa compreensão do desenvolvimento infantil, entendemos ser necessário construirmos uma proposta educativa para a formação da criança pequena que não prescinda da escola de educação infantil, mas que possa efetivamente convertê-la em um espaço desenvolvente para todas as crianças. Reafirmamos o ensino escolar como prática mediadora no interior da prática social global (SAVIANI, 1987) que carrega a potencialidade de enriquecer e complexificar - em uma palavra: humanizar - a atividade da criança pequena.

É decisivo reconhecer a escola como um lugar social conquistado pela classe trabalhadora, que pode permitir erigir condições objetivas para o pleno desenvolvimento infantil, em que pesem as contradições históricas que marcam sua gênese e ainda se presentificam na materialização de objetivos e propostas. O caminho para superação do legado de mazelas que carrega a educação infantil não está, em nosso entendimento, na negação de seu caráter escolar e na recusa ao ato de ensinar que relega ao professor o papel coadjuvante, mas na qualificação do ensino dirigido à criança pequena, embasado no estudo científico do desenvolvimento da criança concreta. É assim que devemos enfrentar o problema da especificidade, empreendendo a luta para transformar a escola de educação infantil em um espaço efetivamente humanizador e desenvolvente. Isso requer compreender que atividade de ensino não se opõe à atividade da criança, mas a provoca, promove e potencializa, atuando como força motriz de seu desenvolvimento.

Na educação infantil, o professor, por meio de sua atividade de ensino, ao organizar e orientar a atividade da criança, gradativamente permite que nela se reconstitua a atividade historicamente elaborada e conquistada pelos seres humanos e que se encontra condensada nas produções da cultura (linguagem, arte, ciência, filosofia, cultura corporal). Logo, não pode haver no processo educativo protagonismo ou centralidade - seja do professor e/ou a criança, pois o que o movimenta é a unidade relacional criança-adulto, num intenso processo de comunicação, de contradições e de desenvolvimento.

Por isso uma das ações do professor, por meio da atividade de ensino, é desafiar o psiquismo infantil, mobilizando interesses, necessidades e motivos que coloquem a criança para agir, ativamente e adequadamente, frente às objetivações culturais, conquistando, nesse 
processo, neoformações psíquicas que transformam sua relação com o mundo, engendrando novas capacidades e novas necessidades.

Defendemos que a escola, como um lugar social historicamente conquistado, embora não isento de contradições, contém potencialidade de enriquecer a formação da criança. É preciso demarcar a conquista histórica representada pelo reconhecimento da Educação Infantil como segmento educacional e reafirmar a função social da escola para a criança de 0 a 5 anos em sua finalidade, enquanto instituição educativa, sob pena de se diluir as fronteiras com outras agências socializadoras, como já apontado por Arce (2004). Trata-se de construir possibilidades educativas no interior da escola de educação infantil capazes de articular conteúdos e formas de ensinar que possam, a cada momento de vida da criança, ser promotoras de humanização e emancipação, considerando as peculiaridades e necessidades de cada período do desenvolvimento, bem como as condições particulares-concretas nas quais ensinamos.

\section{Considerações Finais}

Apostamos no ensino desenvolvente como uma atividade particular no seio da prática social para promover e elevar o desenvolvimento infantil em direção à sua humanização. Contudo, tal aposta sofre pressões e resistências históricas tanto do ponto de vista teórico, com elaborações focadas na criança-protagonista, como das forças sociais que trabalham para a reprodução da ordem via práticas de arremedo social sintetizadas nos ideários da criançacarente.

A situação que se instalou no país com a pandemia do novo coronavírus, que impôs, dentre outras medidas, a suspensão do funcionamento presencial das escolas, pôs a lume a persistência histórica das contradições e mazelas que marcam a educação infantil apontadas ao longo desse artigo. Em sua maioria, os encaminhamentos das redes públicas e privadas para continuidade da atividade de ensino à distância, pela via do que foi denominado ensino remoto emergencial, demonstram de forma patente a ausência de clareza da finalidade pedagógica dessa etapa educacional e de sua especificidade.

Vimos ressuscitar - ou será que nunca morreram? - práticas centralizadas na exposição descontextualizada das crianças a letras e números, típicas da pré-escola preparatória dos anos 1970. A atividade infantil se viu reduzida a tarefas orientadas muito 
mais pela preocupação de cumprir os protocolos e exigências burocráticas de comprovação da realização do ensino remoto do que com as reais necessidades de educação e cuidado de nossas crianças pequenas nesse cenário tão nuvioso. Acrescenta-se a isso o agravante de se delegar às famílias a função de controlar e assistir a (pseudo) realização do conteúdo escolar, colaborando, intencionalmente ou não, para descaracterizar a profissionalidade da docência na educação infantil.

Evidentemente, são múltiplas e complexas as determinações e mediações que se sintetizam nesse triste quadro. O que nos cabe destacar, ao pensar as contradições e potencialidades da escola de educação infantil como espaço formativo para a criança pequena, é o imperativo de salvaguardar as conquistas históricas em defesa dos direitos da criançacidadã a uma educação infantil de qualidade, socialmente referenciada, pública, gratuita e universal, sobrepujando definitivamente a ação orientada a finalidades extrínsecas de caráter preparatório e compensatório, e avançando na construção de uma proposta educativa para a criança-concreta, que se constitui na e pela atividade social, garantindo o pleno desenvolvimento de suas capacidades psíquicas, como potencialidades do devir-humano.

\section{Referências}

ARCE, A. Pedagogia da infância ou fetichismo da infância? In: DUARTE, N. (org.) Crítica ao fetichismo da individualidade. Campinas: Autores Associados, 2004.

BOZHOVICH, L. I. La personalidad y su formación en la edad infantil: investigaciones psicológicas. La Habana, Cuba: Pueblo y Educación, 1981.

CERISARA, A. B. Por uma pedagogia da Educação Infantil: desafios e perspectivas para as professoras. In: SÃO PAULO. Secretaria Municipal de Educação. Diretoria de Orientação Técnica (SME DOT/ ATP/ DOT). Caderno Temático de Formação II - Educação Infantil: Construindo a pedagogia da infância no município de São Paulo. São Paulo: SME/SP, 2004.

CIVILETTI, M. V. P. O cuidado às crianças pequenas no Brasil escravista. Cadernos de Pesquisa, n.73, fev, 1991.

ELKONIN, D. B. Sobre el problema de la periodizacion del desarrollo psíquico en la infancia. In: DAVIDOV, V.; SHUARE, M. (Orgs.). La psicología evolutiva y pedagógica en la URSS (antología). Moscú: Progreso, 1987. p. 104-123.

KISHIMOTO, T. M. A pré-escola em São Paulo (1877 a 1940). São Paulo: Edições Loyola: 1988. 
KISHIMOTO, T.; PINAZZA, M. A. Froebel: uma pedagogia do brincar para a infância. In: OLIVEIRA-FORMOSINHO, J.; KISHIMOTO, T.; PINAZZA, M. A. (Org.). Pedagogia(s) da infância: dialogando com o passado: construindo o futuro. Porto Alegre: Artmed, 2007. p. 37-63.

KUHLMANN Jr., M. Infância e educação infantil: uma abordagem histórica. $4^{\mathrm{a}}$ ed. Porto Alegre: Mediação, 2007.

LAZARETTI, L. M. A organização didática do ensino na educação infantil: implicações da Teoria Histórico-Cultural. 204 f. Tese (Doutorado em Educação) - Universidade Federal de São Carlos, São Carlos/SP, 2013.

LEONTIEV, A. N. Uma contribuição à teoria do desenvolvimento da psique infantil. In: VIGOTSKII, L. S.; LURIA, A. R.; LEONTIEV, A. N. Linguagem, desenvolvimento $e$ aprendizagem. Trad. Maria da Penha Villalobos. São Paulo: Ícone, EDUSP, 1988. p. 59-83.

MARCELINO, E. C. A. O jardim de infância anexo à Escola Normal de São Paulo: Análise do modelo didático-pedagógico. Revista de Iniciação Científica da FFC, v. 4, n. 1, 2004.

MERISSE, A. Origens das instituições de atendimento à criança pequena: o caso das creches. In: ___ [et al]. Lugares da infância: reflexões sobre a história da criança na fábrica, creche e orfanato. São Paulo: Arte \& Ciência, 1997.

MÚJINA, V. Características Psicológicas del prepreescolar y del preescolar. In. PETROVSKI, Aleksander. V. (Org.). La psicología evolutiva y pedagógica. Moscú: Progreso, 1979. p. 44-79.

OLIVEIRA, Z. M. R. Educação Infantil em Creche e Pré-Escola: Concepções e Desafios. In: Caderno de textos $-1^{\text {a }}$ Conferência Municipal de Educação de Contagem, 2005. Disponível em: www.fundep.ufmg.br/ concursos/funec/arquivos/ CadernoDeTextos.htm. Acesso em: 12 dez. 2005.

PASQUALINI, J. C.; MARTINS, L. M. A educação infantil em busca de identidade: análise crítica do binômio cuidar-educar e da perspectiva anti-escolar em educação infantil. Psicol. Educ., n. 27, 2008, pp. 71-100.

ROCHA, E. A. C. A pesquisa em Educação Infantil no Brasil: Trajetória recente e perspectiva de consolidação de uma Pedagogia da Educação Infantil. Florianópolis: UFSC, Centro de Ciências da Educação, Núcleo de Publicações, 1999.

ROSEMBERG, F. Organizações multilaterais, estado e políticas de educação infantil. Cadernos de Pesquisa, n.115, mar, 2002.

SAVIANI, D. Escola e democracia: teorias da educação, curvatura da vara, onze teses sobre educação e política. 17 ed. São Paulo: Cortez: Autores Associados, 1987. 
129 Polyphonía, v. 32/2, jul./dez. 2021

SAVIANI, D. A nova lei da educação: trajetória, limites e perspectivas. Campinas: Autores Associados, 1997.

VIGOTSKII, L. S. La imaginación y el arte em la infância (ensayo psicológico). 4. ed. Madrid: Akal, 1998. 